\title{
A survey of patient and physician acceptance of skin toxicities from anti-epidermal growth factor receptor therapies
}

\author{
Bernd Tischer $^{1} \cdot$ Martina Bilang $^{1} \cdot$ Matthias Kraemer $^{2} \cdot$ Philippe Ronga $^{2} \cdot$ \\ Mario E. Lacouture ${ }^{3}$
}

Received: 20 July 2017 / Accepted: 23 October 2017 / Published online: 7 November 2017

(C) The Author(s) 2017. This article is an open access publication

\begin{abstract}
Background Inhibition of the epidermal growth factor receptor (EGFR) extends patient survival in multiple tumor types. Skin toxicities are the most common adverse event (AE) elicited by EGFR inhibitors. Here, we provide deeper insights into patients' and physicians' acceptance of the risk/benefit trade-offs of skin toxicities during cancer therapy, including comparison of their perceptions and experiences with dermatologic AEs.

Methods A multinational survey of 195 patients and 120 physicians was conducted to gauge attitudes regarding skin toxicities as an $\mathrm{AE}$ during cancer therapy.

Results Skin toxicities were identified by patients and physicians as the $\mathrm{AE}$ that is most discouraging to patients when undergoing cancer therapies. Skin toxicities were cited as
\end{abstract}

Electronic supplementary material The online version of this article (https://doi.org/10.1007/s00520-017-3938-7) contains supplementary material, which is available to authorized users.

Mario E. Lacouture

LacoutuM@mskcc.org

Bernd Tischer

bernd.tischer@kantarhealth.com

Martina Bilang

martina.bilang@kantarhealth.com

Matthias Kraemer

matthias.kraemer@merckgroup.com

Philippe Ronga

philippe.ronga@merckgroup.com

Kantar Health, Munich, Germany

2 Merck KGaA, Darmstadt, Germany

3 Memorial Sloan Kettering Cancer Center, 1275 York Avenue, New York, NY 10065, USA causing pain, impairing quality of life, and proving difficult to manage. Despite these negative influences, the majority of patients $(71 \%)$ indicated they were willing to accept skin toxicities as an AE of an effective therapy. Indeed, the majority of patients and physicians preferred a more effective therapy that induces more severe skin toxicities than a less efficacious therapy that induces less severe skin toxicities; interestingly, patients were willing to accept a higher likelihood of severe skin toxicities than physicians.

Conclusion In this examination of patients' perspectives, we found that patients were willing to accept skin toxicities if they were the anticipated byproduct of a more effective therapeutic regimen. Important differences were observed between patients' and physicians' attitudes regarding risk/benefit tradeoffs during cancer therapy, suggesting that patient's considerations and shared decision-making are key to cancer care.

Keywords EGFR inhibitors · Skin toxicity $\cdot$ Patient perspective $\cdot$ Survey

\section{Introduction}

Epidermal growth factor receptor (EGFR) inhibition is an established, effective therapeutic option for patients with colorectal cancer (CRC) [1], squamous cell carcinoma of the head and neck (SCCHN) [2], lung cancer [3, 4], and pancreatic cancer [5]. Many EGFR inhibitors are approved for clinical use, including monoclonal antibodies (e.g., cetuximab, necitumumab, and panitumumab) and tyrosine kinase inhibitors (including afatinib, erlotinib, gefitinib, lapatinib, and osimertinib). Many of these agents are standard-of-care treatments across multiple indications. Although EGFR inhibitors improve patient survival, they are also associated with skin toxicities. Indeed, the most common adverse event (AE) 
attributable to EGFR inhibitors is mild to moderate acneiform rash, but it can be severe in up to $18 \%$ of patients [6-8]. EGFR inhibitor-elicited skin toxicities begin as edema and erythema during the first weeks of therapy, followed by acneiform eruptions and crusting, and ultimately paronychia and fissure $[9,10]$. Other dermatologic AEs (dAEs) that can accompany EGFR inhibitor therapy include skin aging, xerosis, hair changes, and pruritus [11-13]. These skin toxicities can be painful and debilitating, thereby potentially affecting patients' quality of life (QoL) and adherence to therapy [12-16].

The most widely used grading method is the National Cancer Institute Common Terminology Criteria for Adverse Events version 4.0 (NCI-CTCAE v4.0) itself, which categorizes skin toxicities as grades $1-5$ based on a defined physician-assessed scoring system that takes into account the percentage of the body that is impacted [17]. Therefore, this method was used to evaluate skin toxicities in this survey, with a simplified scale including only grades 1 to 3 , because grade 4 and 5 events are extremely rare.

A previously performed structured literature search revealed an unmet need for research regarding the influence of dAEs on patients' QoL and their acceptance of cancer treatments [18]. Specifically, systematic studies that compare the impact of dAEs vs other AEs on therapeutic decisions from patients' and physicians' perspectives were identified as absent. Accordingly, the purpose of the present survey analysis was to provide deeper insights into patients' and physicians' acceptance of the risk of skin toxicities during cancer therapy, including a comparison of patients' and physicians' viewpoints and an examination of their perceptions regarding acceptable risk/benefit trade-offs.

\section{Methods}

\section{Survey design}

The full patient and physician questionnaires are included in the Online Supplemental Materials (Supplemental Figs. S1 and S2). During the interviews, two different perspectives on the degree of skin rash severity were measured: those of physicians (standardized categorization per the guidelines) and of patients (perceived).

For the risk/benefit trade-off analysis, 192 patients were asked to imagine a hypothetical scenario in which a new second-line therapy was available to treat their cancer. The new therapy was described to have better efficacy than currently available alternatives, but was explicitly defined as non-curative. However, the new therapy was also assumed to elicit severe skin toxicities for 6 to 8 weeks in a certain percentage of patients; the skin toxicities were defined as potentially impairing normal daily function. Given these parameters, the patients were then asked whether they would take the new therapy if the risk of severe skin toxicities was $0 \%$. If they answered "yes," the same question was posed with the risk of severe skin toxicities now being $10 \%$ higher; the exercise was repeated (continuing to use 10\%increase intervals) until the respondents answered "no." Physicians were asked to estimate the percentage of patients who would accept a cancer therapy that causes severe skin rash at different risk levels.

Detailed methods and statistical analyses are described in the supplemental material.

\section{Results}

\section{Characteristics of the survey respondents}

This multinational survey queried 195 patients with CRC, SCCHN, lung cancer, or pancreatic cancer in Europe and the USA (Supplemental Table S1). Notably, 148/195 surveyed patients had received an EGFR inhibitor (afatinib, cetuximab, erlotinib, gefitinib, and/or panitumumab) previously. Baseline characteristics between the EGFR inhibitor-experienced vs EGFR inhibitor-naïve groups ( $n=47)$ of patients were similar, with the exception of the proportion of patients with lung cancer (65 vs $35 \%$ of patients, respectively) and (expectedly) the incidence of reported skin toxicities (90 vs $55 \%$ of patients, respectively). Detailed baseline characteristics are described in the supplemental material.

Skin toxicities experienced by the 195 respondents included rash (67\%), dryness (56\%), itching (43\%), brittle/ingrown nails (31\%), inflammation around the nails (29\%), skin color changes (29\%), and unwanted hair growth (18\%). For many patients, skin toxicities had an impact on their activities of daily living (Fig. S1, Q34). Of the patients who experienced skin toxicities $(n=158), 45 \%$ were fully active and able to carry out daily activities, $39 \%$ were restricted in carrying out physically strenuous activities, $11 \%$ were capable of walking and self-care but not of working, and 5\% were mostly/ completely confined to a bed or chair. Of the 35 respondents who experienced severe skin toxicities, 25 (71\%) were fully active or only restricted from strenuous activity, and 10 (29\%) were either unable to work $(n=4)$ or confined mostly/ completely to a bed or chair $(n=6)$.

Among the 120 surveyed physicians (Supplemental Table S2), 68\% were medical oncologists, who actively treated an average of 322 cancer patients over the past 6 months, representing the following indications: (all advanced/metastatic) CRC ( $n=66)$, SCCHN $(n=22)$, lung cancer $(n=70)$, and pancreatic cancer $(n=20)$, plus an average of 144 patients with other cancer types actively managed over the past 6 months. 
Patients' and physicians' perspectives regarding the impact of various AEs on patients' acceptance of cancer therapy

Of the 158 patients who experienced skin toxicities, $13 \%$ considered stopping the therapy, and $7 \%$ followed through on that decision (Fig. S1, Q28). Similarly, physicians stopped the treatment regimen in $10 \%$ of patients within the subgroup who experienced skin toxicities despite maintaining an Eastern Cooperative Oncology Group performance status (ECOG PS) of 0 or 1 . Conversely, $84 \%$ of respondents who experienced skin toxicities $(n=158)$ said they would choose the same therapy again, at similar rates between EGFR inhibitor-experienced and EGFR inhibitor-naïve patients (83 and $85 \%$, respectively). These findings suggest that although dAE-related QoL is important during cancer treatment, patients are willing to tolerate skin and other toxicities in order to continue treatment. Therefore, patient perspectives can be informative to physicians and should thus be incorporated into a shared decision-making model of therapy planning.

Interestingly, patients' attitudes towards AEs can shift during the course of therapy (Fig. S1, Q21-22). Specifically, at diagnosis, 59\% of 195 respondents were willing to accept any treatment regardless of AEs, whereas during or after therapy, $15 \%$ of patients reported a reduced willingness to accept all types of AEs. Furthermore, $67 \%$ of patients who experienced dAEs $(n=158)$ reported that they would have accepted a higher level of risk of skin toxicities at the time of first cancer diagnosis than at the time they were interviewed for this study.

To gauge which $\mathrm{AE}(\mathrm{s})$ may be most discouraging to patients in terms of accepting a cancer therapy, a pairedcomparison exercise was performed. Of 195 surveyed patients, skin toxicities (grade 3 ) and nausea/vomiting were significantly more impactful than fatigue and hair loss $(p<.001)$ (Fig. 1a). Similarly, skin toxicities (grade 3 ) were significantly more discouraging than nausea/vomiting, fatigue, and hair loss in the survey of 120 physicians $(p<.001)$ (Fig. 1b). When asked to identify the source of unpleasant or negative experiences pertaining to their cancer therapy, nearly half (45\%) of 148 survey respondents treated with an EGFR inhibitor mentioned (severe) skin toxicities. In contrast, $10 \%$ of EGFR inhibitor-experienced patients mentioned fatigue and $7 \%$ mentioned nausea/vomiting. Taken together, these observations suggest that skin toxicity is the AE that is most impactful to patients in terms of accepting a cancer therapy.

\section{Patients' and physicians' perspective regarding why skin toxicities were rated as the most bothersome cancer therapy-related $\mathbf{A E}$}

Of the 159 patients included in the survey who had experienced skin toxicities as an $\mathrm{AE}$ associated with their cancer therapy, 47 patients (approximately 30\%) identified skin toxicities as the most bothersome $\mathrm{AE}$ compared to other AEs. Of the 47 respondents, $40 \%$ rationalized their ranking due to feeling bad, sick, or feeling discomfort; feeling ashamed for esthetic reasons (28\%), pain (26\%), and impact on daily life $(13 \%)$ were also commonly cited. Physicians, who rated skin toxicities as more discouraging than at least one other AE when selecting a therapy to prescribe $(n=115)$, mentioned that being less manageable than other AEs and having an impact on patients' QoL are the predominant reasons; similarly, 179 surveyed patients who rated skin toxicities as more discouraging than at least one other $\mathrm{AE}$ reported that they were principally discouraged by the impact on their QoL, the associated pain and the duration and extent of the skin toxicity (Table 1).

\section{Patients' perspective on experiencing skin toxicities and the impact of skin toxicities on daily living}

Of 159 patients who experienced a skin toxicity, $67 \%$ initially (i.e., their first reaction to a skin toxicity occurring) had a negative perception (e.g., esthetic concerns, frustration, or anxiety), 35\% reported a neutral position (they expected/ understood that skin toxicities were likely to occur), and $21 \%$ accepted the occurrence of skin toxicities as a consequence of their therapy (Table 2). Thus, the response to dAEs was mixed, and many patients provided both positive and negative statements about their initial experiences. Interestingly, in the survey of 120 physicians, when talking with their patients about skin toxicities as possible side effects of their therapy, the rate of patients' acceptance was perceived to be much higher than it was in the self-reported patient survey (patients describing their reaction to the first appearance of skin toxicity, 63 vs $21 \%$ ), where acceptance meant that skin toxicities were seen as a necessary part of therapy and not a predominant source of distress (Table 2; Fig. S1, Q26; Fig. S2, Q36). The 63\% of physicians who described their patients as accepting of dAEs proposed the wide availability of preventative treatments and trust in the physician as justifications. Patients treated with EGFR inhibitors who experienced skin toxicities $(n=132)$ confirmed that dAEs had an impact on social-emotional and functional aspects of their lives (Table 3). Furthermore, $40 \%$ reported itching of the scalp, $27 \%$ felt unattractive, $24 \%$ reported that their mood was affected, $22 \%$ felt embarrassed, $21 \%$ felt the skin toxicities interfered with their social life, and $19 \%$ avoided going out in public. Thus, patients felt that skin toxicities were bothersome for a variety of reasons that impinge upon their QoL. Female patients reported significantly more often than males that dAEs had an emotional or social impact (e.g., feeling unattractive, feeling embarrassed, skin condition interfered with social life, "I avoided going out in public"). Among the 35 surveyed patients who experienced severe dAEs, nearly half agreed that dAEs interfered with their social life. Furthermore, 
Fig. 1 Paired-comparison exercise to gauge which adverse event(s) may be most discouraging to patients in terms of accepting a cancer therapy: a patients' and b physicians' perspectives. Respondents were asked to select the more discouraging $\mathrm{AE}$ in a series of pairs of possible answers. $* * p<.001$ (binomial test) a

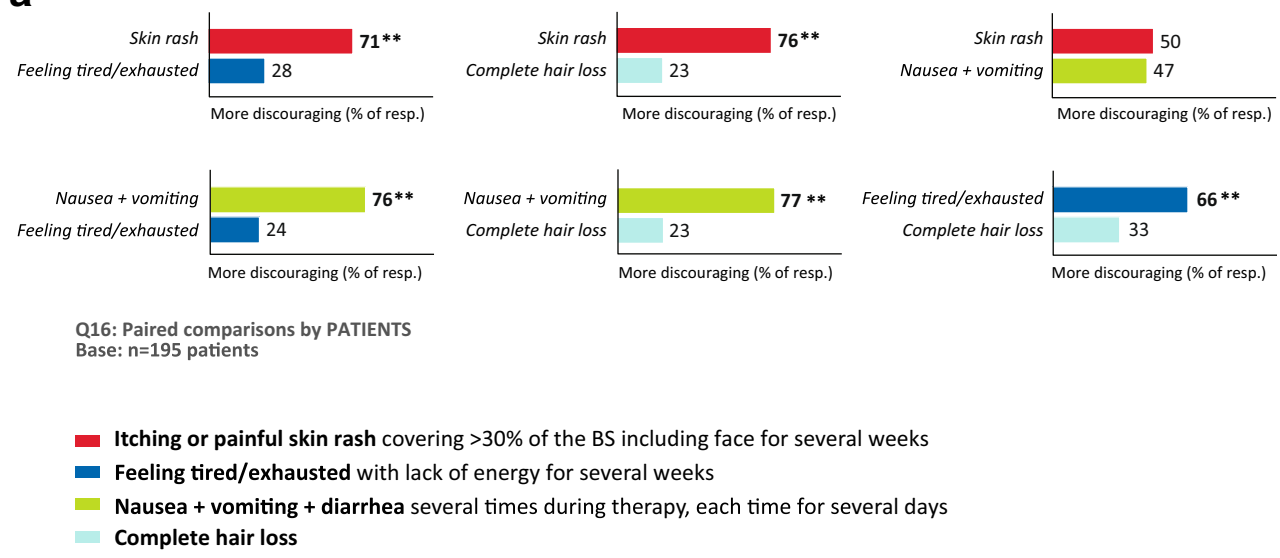

b
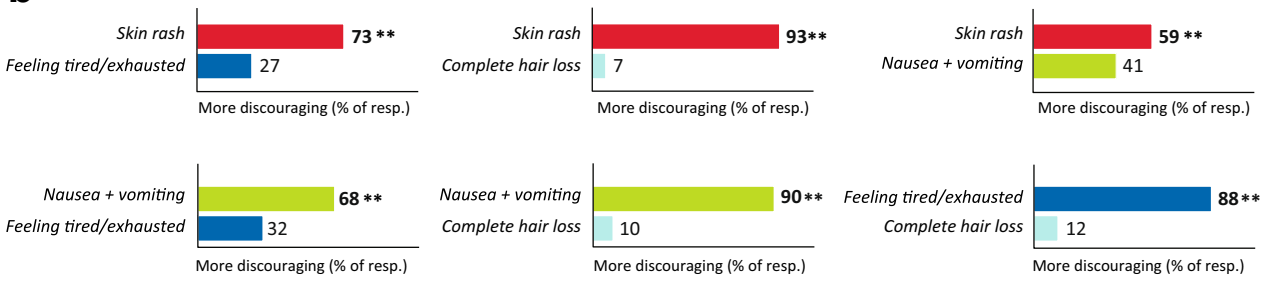

Q7: Paired comparisons by PHYSICIANS Base: $n=120$ physicians

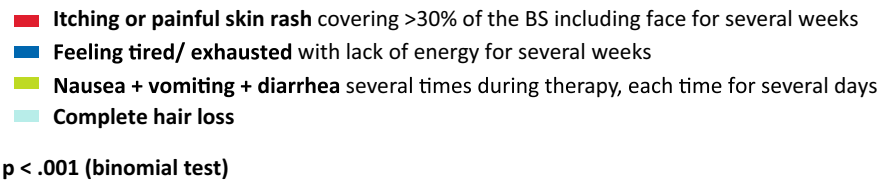

$>40 \%$ felt unattractive and $29 \%$ reported that their ability to sleep was affected. Finally, the sensitivity of their fingernails made it difficult for one-third of the patients to perform household tasks.

Interestingly, $>40 \%$ of surveyed physicians believed that the patients' interpersonal interaction was the QoL social aspect that was most affected. Additionally, 39\% of physicians felt that dAEs affected patients' desire to be with other people, $21 \%$ agreed that dAEs led patients to tend to stay at home, $31 \%$ believed that dAEs had an effect on patients' work or hobbies, and $18 \%$ felt that dAEs made patients feel ashamed. Finally, 30\% felt that skin toxicities affected patients' sleep.

\section{Physician-patient communication regarding skin toxicities}

Of 195 surveyed patients, $71 \%$ felt well-informed about their cancer therapy; somewhat fewer patients $(64 \%)$ felt wellinformed about skin toxicities as a possible $\mathrm{AE}$ of cancer therapies. 4 and $9 \%$ of patients felt that they had not been sufficiently well-informed about their therapy and the potential for skin toxicities, respectively. Notably, EGFR inhibitorexperienced patients felt significantly better informed about skin toxicities than did EGFR inhibitor-naïve patients (70 vs $45 \%$, respectively; $p=.001$ ). In addition, $90 \%$ of the patients who received EGFR inhibitor-based therapy reported that they had been informed regarding toxicities restricted to the skin as a possible AE, but only 46 and $38 \%$ had been warned of possible nail toxicities and hair toxicities, respectively. $92 \%$ of the 147 (1 patient did not answer the question) surveyed patients who were treated with an EGFR inhibitor had heard or read information about skin toxicities as a possible AE of their therapy. Of these patients, $88 \%$ reported having been informed via conversations with doctors, whereas $<30 \%$ of patients indicated that they had been informed via the internet (28\%), conversations with nurses (22\%), other patients (20\%), cancer brochures (17\%), pharmaceutical companies (9\%), a patient support community (6\%), a magazine article (3\%), friends/relatives (3\%), or an information event for patients (1\%) (Fig. 2).

\section{Patient acceptance of skin toxicities}

Of 195 surveyed patients, 85\% agreed that a good QoL, despite receiving cancer therapy, is very important. Furthermore, 
Table 1 Patients' and physicians' perspectives on why itchy or painful skin toxicities were rated as the most bothersome cancer therapy-related adverse event. Patients were asked an open-ended question for why itching or painful skin rash covering more than $30 \%$ of the body surface including the face would discourage them from accepting the therapy. Physicians were asked whether risk of itching or painful rash covering more than $30 \%$ of the body surface, including the face, would discourage them from prescribing a therapy

\begin{tabular}{l} 
Physicians $(n=115)$ \\
\hline Impact on QoL $(84 \%)$ : \\
- More/very bothersome/annoying/burdensome \\
(than other AEs) (33\%) \\
- Impact on QoL (in general) $(28 \%)$ \\
- Esthetic appearance/visual impact (12\%) \\
- Emotional impact (5\%) \\
- Impact on social life, skin rash is stigmatizing (10\%) \\
- Functional impact (esp. sleeping problems) (10\%) \\
- Affects daily life (4\%) \\
Manageability ( $46 \%)$ : \\
- Less manageable than other AEs, insecurity about \\
handling and outcome (19\%) \\
- Lack of patient compliance/non-acceptance of therapy \\
by patient (15\%) \\
- Risk of superinfections and allergic toxicities (14\%) \\
- Skin rash treatments frequently required therapy \\
pauses or discontinuation due to adverse events (13\%) \\
Pain (10\%): \\
- Subjective intolerance towards pain (10\%) \\
Duration and extent of skin rash ( $0 \%)$ :
\end{tabular}

Physicians $(n=115)$

Impact on QoL (84\%):

More/very bothersome/annoying/burdensome

other AEs) $(33 \%)$

- Emotional impact (5\%)

- Impact on social life, skin rash is stigmatizing (10\%)

- Functional impact (esp. sleeping problems) (10\%)

Less manageable than other AEs, insecurity about

by patient $(15 \%)$

- Risk of superinfections and allergic toxicities (14\%)

Skin rash treatments frequently required therapy Pain $(10 \%)$ :

Duration and extent of skin rash $(0 \%)$ :
Patients $(n=179)$

Impact on QoL (70\%):

- More/very bothersome/annoying/burdensome (than other AEs) (20\%)

- Emotional impact (27\%)

- Esthetic appearance/visual impact (26\%)

- Functional impact (sleeping problems, cleaning, dressing) (13\%)

- Impact on social life, skin rash is stigmatizing (7\%)

- Affected daily life (4\%)

Manageability (18\%):

- Difficult handling and manageability of skin rash: (appeared) less manageable than other AEs, insecurity about outcome (9\%)

- Non-acceptance of therapy by patient (3\%)

- Risk of superinfections and allergic toxicities (4\%)

- Skin rash treatments frequently required therapy pauses or discontinuation due to adverse events $(2 \%)$

Pain (30\%):

- Painfulness, in general (subjective intolerance of pain) (30\%)

Duration and extent of skin rash (24\%):

- Continuous nature and extent (spread + duration) of skin rash, i.e., it seemingly "never ends" (infinite pain, soreness, itching) (24\%)

$A E$ adverse event, $Q o L$ quality of life

$54 \%$ believed that their physical condition during therapy should not affect their family life or social activities very much. $58 \%$ of patients agreed that they prefer the most efficacious therapy regardless of possible AEs. However, $58 \%$ also agreed that if a cancer therapy induces severe AEs, they would prefer a different therapy with less severe AEs. Similar findings were obtained from the subgroups of surveyed patients treated with an EGFR inhibitor $(n=148)$ and those not treated with an EGFR inhibitor $(n=47)$. When queried specifically regarding their attitudes towards skin toxicities, $71 \%$ of the 195 surveyed patients indicated that they were willing to accept skin toxicities as a possible AE, so long as the cancer therapy helps to treat their disease. However, $50 \%$ of the patients further acknowledged that these therapy-induced skin toxicities would negatively impact their QoL. Notably, 61\% of the patients would choose a more efficacious therapy that induces more severe skin toxicities vs a less efficacious therapy that induces less severe skin toxicities. This preference was significantly more frequent among the 148 surveyed patients who had been treated with an EGFR inhibitor vs the 45 patients who had not been treated with an EGFR inhibitor (66 vs $45 \%$, respectively; $p=.007$ ). Consistent with the patients' preferences, $56 \%$ of surveyed physicians would prescribe for the majority of their patients a more efficacious EGFR inhibitor therapy that induces more severe skin toxicities vs a less efficacious therapy with less severe skin toxicities.

\section{Patient and physician risk/benefit trade-off exercise}

The results of the hypothetical scenario used to assess patient perception of the risk/benefit trade-offs during cancer therapy are summarized in Fig. 3. 50\% of patients were willing to accept a $56 \%$ probability of severe skin toxicities. A similar hypothetical scenario was posed to 118 physicians, who were asked to estimate what percent of their patients would be willing to accept each risk level of skin toxicities. Interestingly, merely a $32 \%$ probability of severe skin toxicities - in addition to nearly all patients developing mild skin toxicities - was deemed as acceptable for $50 \%$ of their fit, second-line patients with metastatic CRC (ECOG PS of 0 to 1; Fig. 3). Notably, $50 \%$ of patients who had selfreported previously experiencing severe skin toxicities $(n=35)$ were willing to accept a $63 \%$ probability of severe skin toxicities, whereas $50 \%$ of patients who self-reported not having experienced skin toxicities $(n=36)$ were willing to accept only a $55 \%$ probability of severe skin toxicities (Fig. 3b). Similarly, patients who had previously been treated with an EGFR inhibitor $(n=145)$ were willing to accept a higher probability of severe skin toxicities than patients who had not previously been treated with an EGFR inhibitor $(n=47)$ (Fig. 3c). Female and male patients did not differ significantly regarding their acceptance of severe skin toxicities. 
Table 2 Patients' and physician-observed early/initial response to a skin toxicity. Physicians were asked an open-ended question about how their patients react when they talk with them about skin toxicities as possible side effects of their therapy. Patients were asked an open-ended question about their first reaction when they experienced skin reactions

Physicians $(n=120) \quad$ Patients $(n=159)$

Acceptance of AEs $(63 \%)$ :

- Acceptance since (preventive) treatments are available and adjustable to individual needs (22\%)

- Patients tended to accept AEs, although they had concerns because the extent and severity of AEs was not foreseeable (uncertainty) (14\%)

- Patients accepted these AEs, but they could not imagine what consequences these AEs might have (12\%)

- Patients accepted these AEs (and waited to see what happens), because they trusted their physicians $(12 \%)$

- AEs were understood as a sign of efficacy (9\%)

- Patients accepted treatment as second-line but not as first-line therapy (3\%)

- Patients accepted treatment because they are used to AEs in general (from previous therapies) $(3 \%)$

Negative (5\%):

- (Some) patients refused treatment due to the (severe) skin toxicity issue $(5 \%)$

Expected (0\%):

Neutral findings (physicians):

- Esthetic appearance very important: patients lacked confidence when it came to cosmetic issues (pimples, etc.) regarding their appearance (demoralization) (14\%)

- Patients wanted more details on possible AEs and their handling (12\%)

- No particular reaction; the consent was simply being signed (9\%)

- Patients were more worried about their cancer than about adverse events $(8 \%)$

- Patients neglected the fact that skin toxicity may occur; appeared less serious than other toxicities (e.g., liver, kidney) (7\%)

- (Older) patients did not always understand the concept of AEs; generally felt bothered once they occurred (4\%)

- Men reacted more positively than women (4\%)

- Patients were surprised, because they expected typical CT-associated AEs (3\%)

$A E$ adverse event, $C T$ chemotherapy, $Q o L$ quality of life

\section{Discussion}

A general consideration for all anticancer therapies is the accompaniment of efficacy by the risk of potential AEs that impact QoL. The study presented here specifically focused on dAEs and their impact on activities of daily living and QoL, as well as insights into how patients and physicians weigh benefits vs treatment burden of anticancer therapies that could potentially cause a skin toxicity. This multinational survey was prompted by a previous structured literature analysis [18], which identified as missing systematic studies that compare the impact of dAEs vs other AEs on therapeutic decisions from the patients' and physicians' perspectives. The survey included 195 patients and 120 physicians and was conducted to gain deeper insights from both perspectives. The resulting data suggest that skin toxicities are one of the most impactful AEs experienced during cancer therapy due to their strong impact on patient QoL; however, most patients were willing
Acceptance of AEs (21\%):

- Acceptable condition, "no worries";

only mild skin toxicities not/merely affecting QoL (21\%)

- Certainty that skin rash proved the effectiveness of the therapy (9\%)

Negative $(67 \%)$ :

- Embarrassment, disappointment, discomfort about/annoyance with appearance (esthetic reasons) (19\%)

- Frustration, nervousness, anger/aggression (11\%)

- Anxiety/worries (e.g., about effectiveness/adequacy of treatment) (10\%)

Expected (35\%):

- Understood that these toxicities/were told by the physician/was a common $\mathrm{AE}(35 \%)$ 
Table 3 Patients' perspectives regarding impact of skin toxicities on quality of life. Patients were asked to specify whether each of the following conditions applied at a time when the symptoms of the skin toxicities were most severe

\begin{tabular}{|c|c|c|c|c|c|c|c|c|}
\hline & $\begin{array}{l}\% \text { of } \\
\text { total } \\
(n=158)\end{array}$ & $\begin{array}{l}\% \text { of EGFR } \\
\text { inhibitor treated } \\
(n=132)\end{array}$ & $\begin{array}{l}\% \text { of EGFR } \\
\text { inhibitor naïve } \\
(n=26)\end{array}$ & $\begin{array}{l}\% \text { of } \\
\text { mild } \\
(n=53)\end{array}$ & $\begin{array}{l}\% \text { of } \\
\text { moderate } \\
(n=70)\end{array}$ & $\begin{array}{l}\% \text { of } \\
\text { severe } \\
(n=35)\end{array}$ & $\begin{array}{l}\% \text { of } \\
\text { male } \\
(n=79)\end{array}$ & $\begin{array}{l}\% \text { of } \\
\text { female } \\
(n=79)\end{array}$ \\
\hline \multicolumn{9}{|l|}{ Physical impact } \\
\hline My skin or scalp itched & 35 & $40^{1}$ & 8 & 13 & $37^{1}$ & $63^{1,2}$ & 35 & 34 \\
\hline My skin or scalp was dry or "flaky" & 34 & $39^{1}$ & 12 & 13 & $40^{1}$ & $54^{1}$ & 30 & 38 \\
\hline My skin or scalp felt irritated & 34 & 36 & 23 & 11 & $33^{1}$ & $69^{1,2}$ & 28 & $39^{1}$ \\
\hline $\begin{array}{l}\text { I was bothered by sensitivity around my } \\
\text { fingernails or toenails }\end{array}$ & 22 & $24^{1}$ & 8 & 13 & 23 & $31^{1}$ & 19 & 24 \\
\hline $\begin{array}{l}\text { I was bothered by a change in my skin's } \\
\text { sensitivity to the sun }\end{array}$ & 17 & 19 & 8 & 4 & $16^{1}$ & $40^{1,2}$ & 13 & 22 \\
\hline My eyes were dry & 16 & 17 & 15 & 2 & $17^{1}$ & $37^{1,2}$ & 9 & $24^{1}$ \\
\hline My skin bled easily & 11 & $13^{1}$ & 4 & 0 & $13^{1}$ & $26^{1}$ & 10 & 13 \\
\hline \multicolumn{9}{|l|}{ Social-emotional impact } \\
\hline $\begin{array}{l}\text { I felt unattractive because of how my skin } \\
\text { looked }\end{array}$ & 26 & 27 & 19 & 9 & $30^{1}$ & $43^{1}$ & 17 & $35^{1}$ \\
\hline My skin condition affected my mood & 22 & $24^{1}$ & 8 & 8 & $23^{1}$ & $40^{1}$ & 15 & $28^{1}$ \\
\hline I was embarrassed by skin condition & 21 & 22 & 15 & 4 & $31^{1}$ & $26^{1}$ & 10 & $32^{1}$ \\
\hline $\begin{array}{l}\text { I avoided going out in public because of how my } \\
\text { skin looked }\end{array}$ & 18 & 19 & 15 & 2 & $23^{1}$ & $34^{1}$ & 10 & $27^{1}$ \\
\hline I was bothered by hair loss & 9 & 7 & 23 & 15 & 6 & 9 & 9 & 10 \\
\hline I was bothered by increased facial hair & 5 & 5 & 4 & 0 & $9^{1}$ & 6 & 1 & $9^{1}$ \\
\hline \multicolumn{9}{|l|}{ Functional impact } \\
\hline My skin condition interfered with my social life & 20 & 21 & 15 & 4 & $20^{1}$ & $46^{1,2}$ & 11 & $29^{1}$ \\
\hline $\begin{array}{l}\text { Changes in my skin condition made my life } \\
\text { difficult }\end{array}$ & 17 & 17 & 15 & 2 & $19^{1}$ & $37^{1}$ & 10 & $24^{1}$ \\
\hline $\begin{array}{l}\text { My skin condition interfered with my ability to } \\
\text { sleep }\end{array}$ & 15 & 17 & 8 & 2 & $19^{1}$ & $29^{1}$ & 10 & $20^{1}$ \\
\hline $\begin{array}{l}\text { Sensitivity around my fingernails made it } \\
\text { difficult to perform household tasks }\end{array}$ & 12 & 12 & 12 & 4 & 9 & $31^{1,2}$ & 10 & 14 \\
\hline \multirow{2}{*}{$\begin{array}{l}\text { The skin effects from treatment have interfered } \\
\text { with household tasks }\end{array}$} & 6 & 7 & 4 & 4 & 4 & 14 & 4 & 9 \\
\hline & & \multicolumn{2}{|c|}{$\begin{array}{l}{ }^{1} \text { Higher than "EGFR } \\
\text { inhibitor naive" } \\
(p<.05)\end{array}$} & \multicolumn{3}{|c|}{$\begin{array}{l}{ }^{1} \text { Higher than "mild" }(p<.05) \\
{ }^{2} \text { Higher than "moderate" } \\
\quad(p<.05)\end{array}$} & \multicolumn{2}{|c|}{$\begin{array}{l}{ }^{1} \text { Higher than } \\
\text { "male" } \\
(p<.05)\end{array}$} \\
\hline
\end{tabular}

EGFR epidermal growth factor receptor

elicits skin toxicities because they believe these AEs to be less manageable (in addition to impacting patient QoL). This distinction in perceptions suggests that while improvements in the manageability of skin toxicities may make them more acceptable to physicians, patients will continue to view these AEs as discouraging unless specific attributes, such as pain, can be reduced or eliminated. These observations are broadly consistent with the work of Basch and colleagues, who previously reported differences in the grading and perception of skin toxicities between patients and physicians [19-21].

Taken together, these differences underscore the importance of improved communication between patients and physicians: by truly taking into account patients' viewpoint, there is the possibility of improving patient QoL. This shared decisionmaking process allows clinicians and patients to make decisions together in choosing tests and therapies based on data that weigh risks and benefits with patient values and predilections. Shared decision-making may increase patient choice, clinical outcomes, adherence to therapy, and approval of care [22]. For example, given the accumulating clinical evidence supporting the effectiveness of prophylactic management of EGFR inhibitor-attributable skin toxicities [23-30], physicians should not only be well versed regarding this strategy but also be capable of clearly communicating to their patients the existence of preventative measures/treatments for dAEs and the benefits of this approach. Speaking more generally, the importance of improved patient-physician communication is further reinforced by our observation that physicians represented the overwhelmingly predominant source of information for the surveyed patients regarding their disease; indeed, more than three times as many patients treated with EGFR inhibitors reported receiving information regarding skin toxicities as a possible $\mathrm{AE}$ 
Fig. 2 a Patients' perspectives regarding how well-informed they felt about AEs associated with their therapy. EGFR, epidermal growth factor receptor. b EGFR inhibitor-treated patients indicate sources of information about skin toxicities as possible adverse events

\begin{tabular}{|c|c|c|c|c|c|c|c|}
\hline & & \multicolumn{6}{|c|}{ Ever treated with an EGFR inhibitor? } \\
\hline & & \multicolumn{2}{|c|}{ All patients } & \multicolumn{2}{|c|}{$\begin{array}{l}\text { EGFR inhibitor- } \\
\text { treated patients }\end{array}$} & \multicolumn{2}{|c|}{$\begin{array}{c}\text { EGFR inhibitor-naive } \\
\text { patients }\end{array}$} \\
\hline & & $\begin{array}{l}\text { Absolute } \\
\text { number }\end{array}$ & $\%$ of total & $\begin{array}{l}\text { Absolute } \\
\text { number }\end{array}$ & $\%$ of total & $\begin{array}{l}\text { Absolute } \\
\text { number }\end{array}$ & $\%$ of total \\
\hline \multirow{4}{*}{$\begin{array}{l}\text { 15A. Statement: I } \\
\text { feel well informed } \\
\text { about my therapy }\end{array}$} & Total & 195 & 100 & 148 & 100 & 47 & 100 \\
\hline & $\begin{array}{l}\text { Completely/ } \\
\text { well informed }\end{array}$ & 138 & 71 & 108 & 73 & 30 & 64 \\
\hline & $\begin{array}{l}\text { Moderately } \\
\text { informed }\end{array}$ & 49 & 25 & 36 & 24 & 13 & 28 \\
\hline & $\begin{array}{l}\text { Not well } \\
\text { informed }\end{array}$ & 8 & 4 & 4 & 3 & 4 & 9 \\
\hline \multirow{4}{*}{$\begin{array}{l}\text { 15B. Statement: I } \\
\text { feel well informed } \\
\text { about skin } \\
\text { toxicities }\end{array}$} & Total & 195 & 100 & 148 & 100 & 47 & 100 \\
\hline & $\begin{array}{l}\text { Completely/ } \\
\text { well informed }\end{array}$ & 125 & 64 & 104 & 70 & 21 & 45 \\
\hline & $\begin{array}{l}\text { Moderately } \\
\text { informed }\end{array}$ & 52 & 27 & 38 & 26 & 14 & 30 \\
\hline & $\begin{array}{l}\text { Not well } \\
\text { informed }\end{array}$ & 18 & 9 & 6 & 4 & 12 & 26 \\
\hline
\end{tabular}

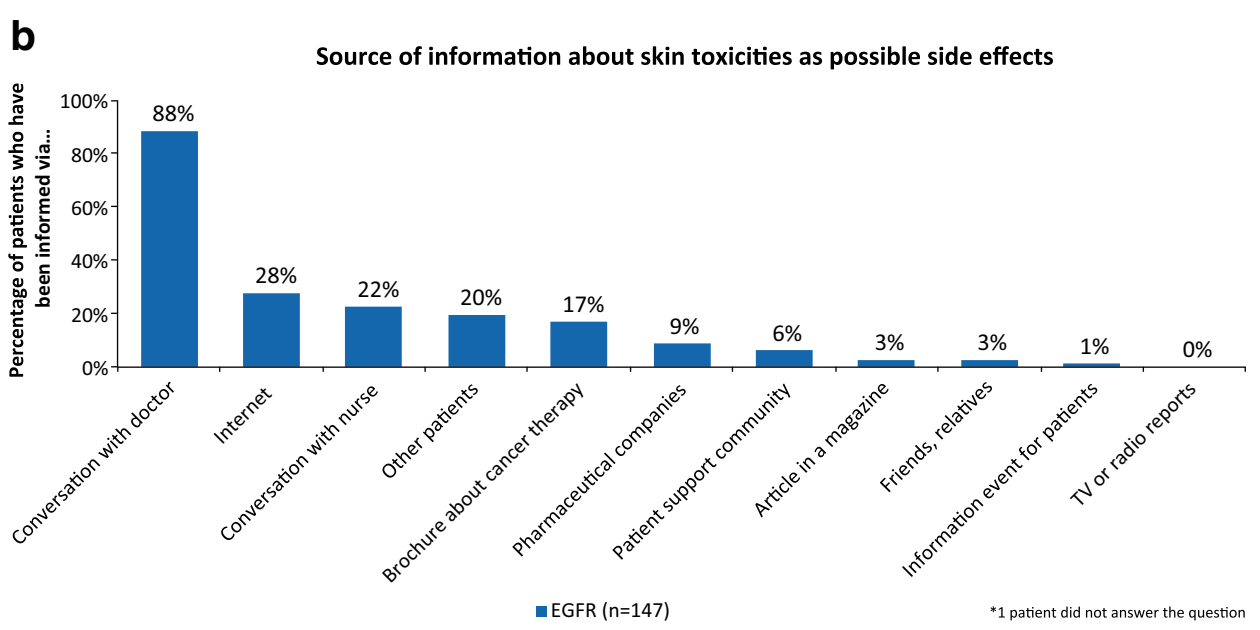

of their therapy from their physicians vs any other sources (e.g., internet, nurses, other patients).

Perhaps our most important finding was the observation that more patients may be willing to tolerate severe skin toxicities than their physicians imagined. Notably, this differential risk/benefit assessment was even more pronounced in the subgroup of surveyed patients who had previously experienced severe skin toxicities - and in the subgroup of patients who had previously been treated with an EGFR inhibitorperhaps reflecting a "fear of the unknown" in patients who have not personally experienced skin toxicities and underscoring the mechanism of anticipatory coping. As alluded to above, one strength of this study was its ability to capture the patients' perspectives, including their attitudes concerning weighing benefit vs risk in their cancer therapy decisions. In contrast, a limitation of this study was that physicians may have imagined an overall different patient cohort (vs the surveyed patients) when asked to estimate the percentage of patients willing to accept a given risk of dAEs during the risk/benefit trade-off exercise. Another limitation was the grouping together of patients with different tumor types, grouping together of patients treated with different EGFR inhibitors (including monoclonal antibodies and tyrosine kinase inhibitors), and, finally, grouping together of patients treated with different lines of therapy. Additionally, as with every survey, there is the possibility that the population of respondents was not representative of the overall patient population (potential self-selection for healthier individuals). Finally, prior to necessitating reactive therapy and/or drug dosage reduction and interruption, prophylactic therapy seems advisable in every patient receiving EGFR inhibitors, unless contraindicated, to prevent grade $\geq 2$ skin toxicities [13, 32].

\section{Conclusion}

In this examination of patients' perspectives, skin toxicities were cited as one of the most discouraging AEs experienced during cancer therapy; however, the majority of patients were willing to accept skin toxicities if they were the anticipated 


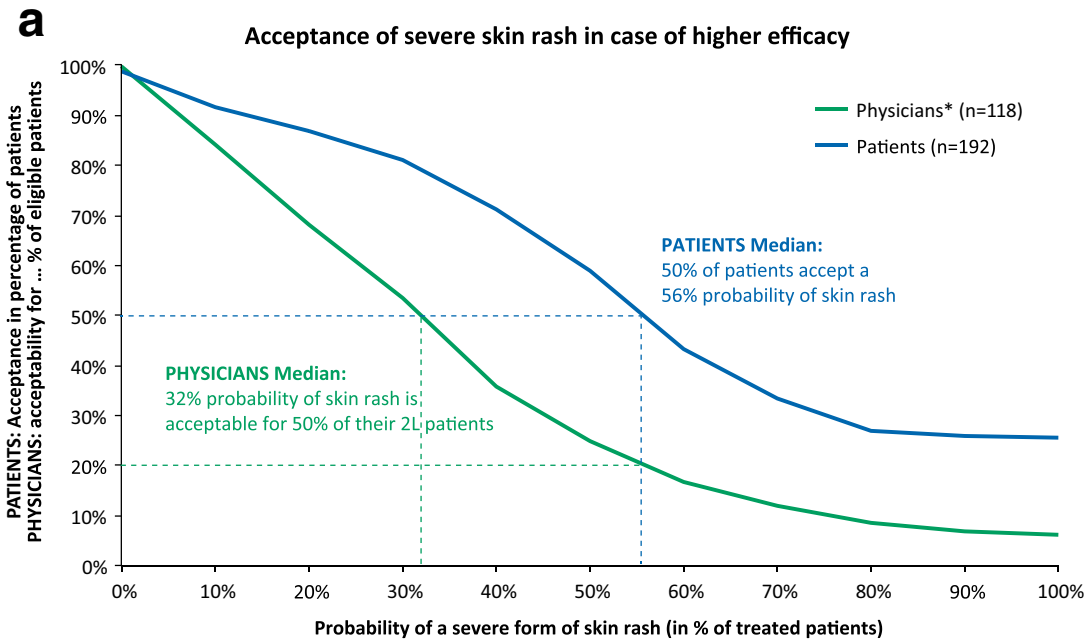

Q18 (physicians: Q19): Trade-Off design

*Physicians: Acceptance for MCRC patients with ECOG 0-1 Base: $\mathrm{n}=192$ patients, 118 physicians

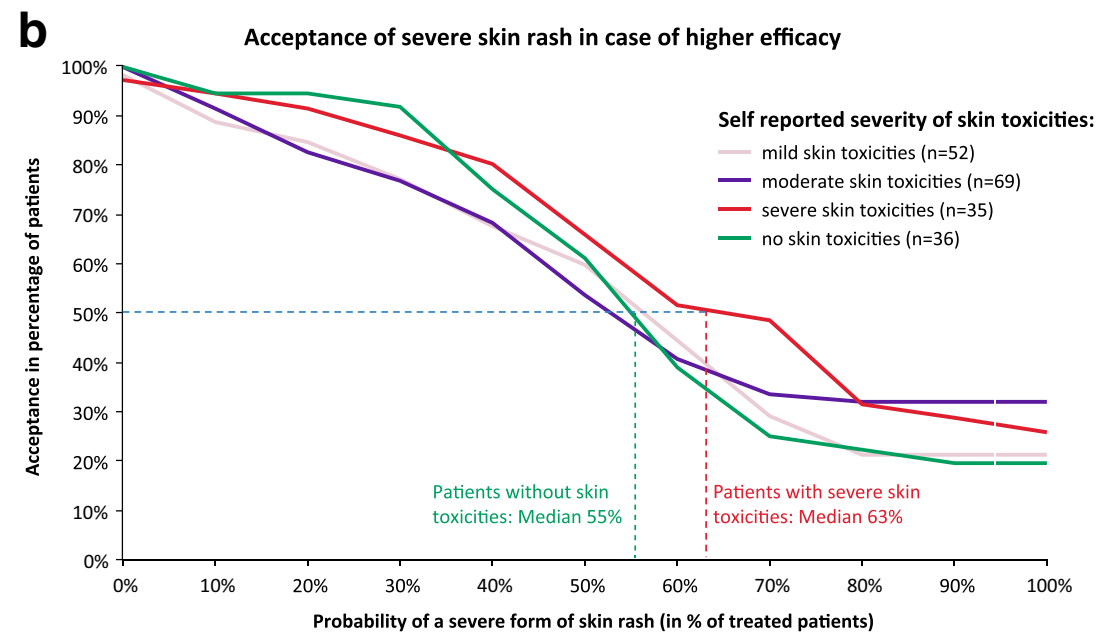

Q18 Trade-Off design Base: $n=192$ patients

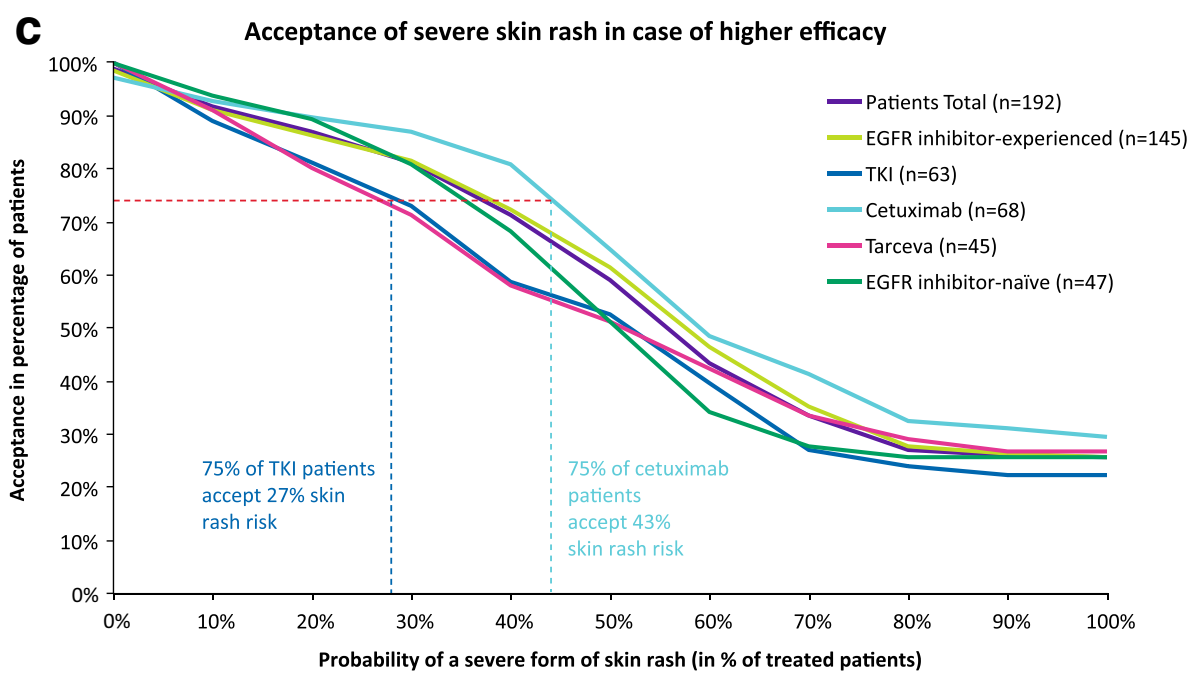


4 Fig. 3 a Patients' and physicians' perspective in a risk/benefit trade-off exercise based upon a defined hypothetical scenario. The scenario involved a newly available, more efficacious therapy for which a greater risk of skin toxicities is implied (see the text and Fig. S1, Q18). Patients were asked at what level of risk of skin toxicities they would switch from willing to unwilling to accept this new treatment. b Patients' perspective in a risk/benefit trade-off exercise based upon a defined hypothetical scenario, stratified based on self-reported severity of skin toxicity. The scenario involved a newly available, more efficacious therapy for which a greater risk of skin toxicity is implied (see text and Fig. S1, Q18). Patients were asked at what level of risk of skin toxicity they would switch from willing to unwilling to accept this new treatment. c Patients' perspective in a risk/benefit trade-off exercise based upon a defined hypothetical scenario, stratified based on self-reported previous treatment experience with EGFR inhibitors.* The scenario involved a newly-available, more efficacious therapy for which a greater risk of skin toxicity is implied (see the text and Fig. S1, Q18). Patients were asked at what level of risk of skin toxicity they would switch from willing to unwilling to accept this new treatment. ECOG, Eastern Cooperative Oncology Group; mCRC, metastatic colorectal carcinoma; Q, question; TKI, tyrosine kinase inhibitor. *3 patients could not complete this section due to emotional distress

byproduct of a more efficacious therapeutic regimen. There were important differences between patients' and physicians' attitudes regarding risk/benefit trade-offs during cancer therapy, suggesting that improved communication between the two has the potential to provide value to patients and may improve cancer care and patient QoL. Communicating to patients the correlation between rash severity and clinical outcome, as well as the availability of preventive and reactive therapies for dAEs, must be part of every discussion to minimize anxiety, decrease frequency and severity of toxicities, and maintain QoL.

Acknowledgements M.E.L. is funded in part through the NIH/NCI Cancer Center Support Grant P30 CA008748. Medical writing assistance was provided by ClinicalThinking, Inc., Hamilton, NJ, USA, and funded by Merck KGaA, Darmstadt, Germany.

\section{Compliance with ethical standards}

\section{Conflict of interest}

- B. Tischer: No conflicts to disclose.

- M. Kraemer: Employee of Merck KGaA.

- P. Ronga: Employee of Merck KGaA.

- M. Lacouture: Consulting for AstraZeneca, Boehringer Ingelheim, Dignitana, Foamix, Genentech, Janssen R\&D, Merck Sharpe-Dohme, EMD Serono, Michael's Mission, Novartis, Oncology Training International, Quintiles, and RP Pharmaceuticals; research grants from Berg, Bristol-Myers Squibb, and Roche. This research was funded in part through the NIH/Cancer Center Support Grant P30 CA008748.

- M. Bilang: No conflicts to disclose.

Open Access This article is distributed under the terms of the Creative Commons Attribution-NonCommercial 4.0 International License (http:// creativecommons.org/licenses/by-nc/4.0/), which permits any noncommercial use, distribution, and reproduction in any medium, provided you give appropriate credit to the original author(s) and the source, provide a link to the Creative Commons license, and indicate if changes were made.

\section{References}

1. Van Cutsem E, Kohne CH, Hitre E et al (2009) Cetuximab and chemotherapy as initial treatment for metastatic colorectal cancer. N Engl J Med 360(14):1408-1417

2. Bonner JA, Harari PM, Giralt J et al (2006) Radiotherapy plus cetuximab for squamous-cell carcinoma of the head and neck. $\mathrm{N}$ Engl J Med 354(6):567-578

3. Pirker R, Pereira JR, Szczesna A et al (2009) Cetuximab plus chemotherapy in patients with advanced non-small-cell lung cancer (FLEX): an open-label randomised phase III trial. Lancet 373(9674):1525-1531

4. Lacouture ME, Keefe DM, Sonis S et al (2016) A phase II study (ARCHER 1042) to evaluate prophylactic treatment of dacomitinibinduced dermatologic and gastrointestinal adverse events in advanced non-small-cell lung cancer. Ann Oncol 27(9):1712-1718

5. Moore MJ, Goldstein D, Hamm J et al (2007) Erlotinib plus gemcitabine compared with gemcitabine alone in patients with advanced pancreatic cancer: a phase III trial of the National Cancer Institute of Canada Clinical Trials Group. J Clin Oncol 25(15): 1960-1966

6. Perez-Soler R, Van Cutsem E (2007) Clinical research of EGFR inhibitors and related dermatologic toxicities. Oncology (Williston Park) 21(11 Suppl 5):10-16

7. Sipples R (2006) Common side effects of anti-EGFR therapy: acneform rash. Semin Oncol Nurs 22(1 Suppl 1):28-34

8. Eilers RE Jr, Gandhi M, Patel JD et al (2010) Dermatologic infections in cancer patients treated with epidermal growth factor receptor inhibitor therapy. J Natl Cancer Inst 102(1):47-53

9. Lacouture ME (2007) Insights into the pathophysiology and management of dermatologic toxicities to EGFR-targeted therapies in colorectal cancer. Cancer Nurs 30(4 Suppl 1):S17-S26

10. Lacouture ME (2006) Mechanisms of cutaneous toxicities to EGFR inhibitors. Nat Rev Cancer 6(10):803-812

11. Gerber PA, Buhren BA, Schrumpf H et al (2016) Mechanisms of skin aging induced by EGFR inhibitors. Support Care Cancer 24(10):4241-4248

12. Valentine J, Belum VR, Duran J et al (2015) Incidence and risk of xerosis with targeted anticancer therapies. J Am Acad Dermatol 72(4):656-667

13. Lacouture ME, Anadkat MJ, Bensadoun RJ et al (2011) Clinical practice guidelines for the prevention and treatment of EGFR inhibitor-associated dermatologic toxicities. Support Care Cancer 19(8):1079-1095

14. Rosen AC, Case EC, Dusza SW et al (2013) Impact of dermatologic adverse events on quality of life in 283 cancer patients: a questionnaire study in a dermatology referral clinic. Am J Clin Dermatol 14(4):327-333

15. Joshi SS, Ortiz S, Witherspoon JN et al (2010) Effects of epidermal growth factor receptor inhibitor-induced dermatologic toxicities on quality of life. Cancer 116(16):3916-3923

16. Burtness B, Anadkat M, Basti S et al (2009) NCCN task force report: management of dermatologic and other toxicities associated with EGFR inhibition in patients with cancer. J Natl Compr Canc Netw 7(Suppl 1):S5-21 quiz S22-4

17. National Cancer Institute. Common terminology criteria for adverse events (CTCAE). Version 4.03. http://evs.nci.nih.gov Web site. http://evs.nci.nih.gov/ftp1/CTCAE/CTCAE_4.03_2010-06-14 QuickReference_5x7.pdf. Updated 2010. Accessed Dec 15, 2015

18. Tischer B, Huber R, Kraemer M, Lacouture ME (2017) Dermatologic events from EGFR inhibitors: the issue of the missing patient voice. Support Care Cancer 25(2):651-660

19. Di Maio M, Gallo C, Leighl NB et al (2015) Symptomatic toxicities experienced during anticancer treatment: agreement between 
patient and physician reporting in three randomized trials. J Clin Oncol 33(8):910-915

20. Basch E, Jia X, Heller G et al (2009) Adverse symptom event reporting by patients vs clinicians: relationships with clinical outcomes. J Natl Cancer Inst 101(23):1624-1632

21. Basch EM, McDonough T, Iasonos A et al (2006) Patient versus clinician symptom reporting using the National Cancer Institute Common Terminology Criteria for Adverse Events. J Clin Oncol 24(18_suppl):8515

22. Fowler FJ Jr, Gerstein BS, Barry MJ (2013) How patient centered are medical decisions?: results of a national survey. JAMA Intern Med 173(13):1215-1221

23. Scope A, Agero AL, Dusza SW et al (2007) Randomized doubleblind trial of prophylactic oral minocycline and topical tazarotene for cetuximab-associated acne-like eruption. J Clin Oncol 25(34): $5390-5396$

24. Deplanque G, Gervais R, Vergnenegre A et al (2016) Doxycycline for prevention of erlotinib-induced rash in patients with non-smallcell lung cancer (NSCLC) after failure of first-line chemotherapy: a randomized, open-label trial. J Am Acad Dermatol. 74(6):10771085

25. Lacouture ME, Mitchell EP, Piperdi B et al (2010) Skin toxicity evaluation protocol with panitumumab (STEPP), a phase II, openlabel, randomized trial evaluating the impact of a pre-emptive skin treatment regimen on skin toxicities and quality of life in patients with metastatic colorectal cancer. J Clin Oncol 28(8):1351-1357

26. Melosky B, Anderson H, Burkes RL et al (2015) Pan Canadian rash trial: a randomized phase III trial evaluating the impact of a prophylactic skin treatment regimen on epidermal growth factor receptortyrosine kinase inhibitor-induced skin toxicities in patients with metastatic lung cancer. J Clin Oncol 10;34(8):810-815

27. Arrieta O, Vega-Gonzalez MT, Lopez-Macias D et al (2015) Randomized, open-label trial evaluating the preventive effect of tetracycline on afatinib induced-skin toxicities in non-small cell lung cancer patients. Lung Cancer 88(3):282-288

28. Kobayashi Y, Komatsu Y, Yuki S et al (2015) Randomized controlled trial on the skin toxicity of panitumumab in Japanese patients with metastatic colorectal cancer: HGCSG1001 study; JSTEPP. Future Oncol 11(4):617-627

29. Hofheinz RD, Deplanque G, Komatsu Y et al (2016) Recommendations for the prophylactic management of skin reactions induced by epidermal growth factor receptor inhibitors in patients with solid tumors. Oncologist 21(12):1483-1491

30. Yamada M, Iihara H, Fujii H et al (2015) Prophylactic effect of oral minocycline in combination with topical steroid and skin care against panitumumab-induced acneiform rash in metastatic colorectal cancer patients. Anticancer Res 35(11):6175-6181 